Oral Section

\title{
Differentiation and modulation of phagocyte activity in murine granuloma after treatment with thymulin $5 \mathrm{cH}$
}

\author{
Leoni Villano Bonamin ${ }^{1,2,3}$, César Sato ${ }^{3}$, Fabiana Santana ${ }^{1}$, Thayná Neves \\ Cardoso $^{1}$, Cideli de Paula Coelho ${ }^{1}$, Lika Osugui ${ }^{4}$, Ana Flávia Popi ${ }^{4}$, \\ Elizabeth Cristina Perez Hurtado ${ }^{1}$
}

\author{
1Universidade Paulista (UNIP), São Paulo, Brazil \\ 2Universidade de Santo Amaro (UNSA), São Paulo, Brazil \\ 3Instituto de Pesquisa e Desenvolvimento Royal, São Roque, Brazil \\ ${ }_{4}^{4}$ Universidade Federal de São Paulo, São Paulo, Brazil
}

\begin{abstract}
Introduction: In previous studies, it was found that thymulin (thymic hormone), when prepared in homeopathic 5CH dilution, can modulate diseases progress and immune processes, such as virus infection in poultry and experimental tumor development. This work aims to study the immune modulatory mechanisms of thymulin $5 \mathrm{CH}$ in granulomatous experimental model induced by BCG in mice, with special focus on the phagocytes differentiation from peritoneal B1 stem cells and on the activity of these cells and lymphocyte cooperation at the injury site. Method: Male adult Balb/c mice were inoculated with BCG into the footpad to induce granuloma and its cells were evaluated by histomorphometric methods (Ziehl-Neelsen staining of macrophages) and flow cytometry. The phenotypic characterization of phagocytes, $\mathrm{T}$ and $\mathrm{B}$ lymphocytes in the peritoneum and regional lymph node was done. Thus, CD11b (activated phagocytes and B1 cells), CD19 (B1 cells and B2), CD23 (B2 cells), CD5 (B1 cell subtypes and T cells), CD4, CD8 (effective T lymphocytes) and CD25 (regulatory lymphocytes) positive cells were quantified. Thymulin 5cH and vehicle (30\% hydro-alcohol solution) groups were treated with 1:2500 diluted drug into the drinking water. Results: After 21 days of infection, the differentiation of B1 peritoneal stem cells into phagocytes reached the peak, being higher in thymulin-treated mice $\left(\mathrm{X}^{2}, \mathrm{p}=0.0001\right)$. Simultaneously, the number of infected phagocytes in the lesion decreased $(\mathrm{KW}, \mathrm{p}=0.001)$, indicating remission of the infection. The number of $\mathrm{B} 1$ derived phagocytes, CD4+ and CD8+ T lymphocytes in the local lymph node increased in thymulin-treated mice $\left(\mathrm{X}^{2}\right.$, $\mathrm{p}=0.0001$ ), at the same time. No difference was seen regarding to CD25+ cells. Conclusion: The results show that thymulin $5 \mathrm{CH}$ treatment is able to improve the granuloma inflammatory process by modulating local and systemic phagocyte differentiation, as well as T cell migration into the local lymph node.
\end{abstract}

Keywords: BCG, granuloma, thymulin, homeopathy, B-1 cells

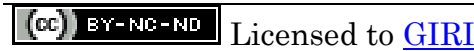

Support: FAPESP 2010/50842-0

Conflict of interest: authors declare there is no conflict of interest

Received: 01 June 2012; Revised: 07 August 2012; Published: 30 September 2012.

Correspondence author: Leoni Villano Bonamin, leonibonamin@gmail.com; leonibonamin@unip.br

How to cite this article: Bonamin LV, Sato C, Santana F, Cardoso TN, Coelho CP, Osugui L, Popi AF, HurtadoECP. Differentiation and modulation of phagocyte activity in murine granuloma after treatment with thymulin $5 \mathrm{cH}$. Int $\mathrm{J}$ High Dilution Res [online]. 2012 [cited YYYY Month dd]; 11(40):148-148. Proceedings of the XXVI GIRI Symposium; 2012 Sep 20-22; Florence (Italy). GIRI; 2012; Available from: http://www.feg.unesp.br/ ojs/index.php/ijhdr/article/view/580/566 